\title{
EL SENTIMIENTO RELIGIOSO EN EL DEBATE POLÍTICO DE 1869 EN ESPAÑA
}

\author{
POR \\ ANA ISABEL GONZÁLEZ MANSO ${ }^{1}$ \\ Universidad del País Vasco
}

\section{RESUMEN}

En este estudio analizamos el concepto de religión y los conceptos cercanos de tolerancia y libertad de conciencia en el seno del debate constitucional que se produjo en España con el fin de establecer la libertad de cultos en 1869. A través del análisis del diferente significado y contenido, que dieron los publicistas del momento a estos conceptos, pretendemos llegar a una mejor comprensión de las diferentes posturas defendidas por los mismos.

PALABRAS CLAVE: Religión; Constitución; España; siglo XIX.

\section{RELIGIOUS FEELINGS IN THE 1869 SPANISH POLITICAL DEBATE}

\section{ABSTRACT}

This work analyses the concept of Religion together with the near concepts of Tolerance and Consciousness Freedom as they were intended in the course of the constitutional debate held in Spain in 1869 with the aim of establishing the Cults Freedom. Through the analysis of the different meanings and contents the Spanish intellectuals gave to these concepts, it is possible to reach a better understanding of the different positions upheld by them.

KEY WORDS: Religion; Constitution; Spain; Ninetheenth Century.

CÓMO CITAR ESTE ARTícUlo / CITATION: González Manso, A. I. 2018. «El sentimiento religioso en el debate político de 1869 en España». Hispania Sacra 70, 142: 601-611. https://doi.org/10.3989/hs.2018.041

$\begin{array}{ll}\text { Recibido/Received } & \text { 09-01-2017 } \\ \text { Aceptado/Accepted } & \text { 19-01-2017 }\end{array}$

La Constitución de 1869 estableció por fin, tras muchos vaivenes constitucionales a lo largo del siglo XIX, la libertad de cultos en España aunque su grado de aplicación será escaso y su vida muy breve. ${ }^{2}$ Para profundizar en las propuestas de plasmación política de esa libertad y entender su fracaso relativo (pues la Constitución de 1869 supuso el inicio de una corriente intelectual impulsora de un nuevo enfoque en el tema de la libertad religiosa) $)^{3}$ vamos a analizar en detalle que entendieron por el concepto de religión los actores en juego. Los conceptos son unidades semánticas muy móviles y por ello éstos deben de ser definidos de acuerdo a su uso real en las situaciones históricas, no solo como indicadores de la realidad pasada sino también como factores e instrumentos del cambio

\footnotetext{
1 Anabel.gonzalez.manso@gmail.com / ORCID iD: http://orcid. org/0000-0002-7193-317X

2 Llamazares Fernández 2011: t. I «Conciencia, tolerancia y laicidad», 132-146.

3 Barrero Ortega 2006: 58.
}

histórico. De hecho el concepto de religión es un concepto difícil de definir pues, como producto histórico que es, ha ido variando a lo largo del tiempo. Las definiciones fallan porque no engloban todos los hechos que en las diferentes civilizaciones podemos considerar «religiosos». Habría que partir de la empírica del empleo del término para llegar a abarcar la totalidad de estos fenómenos. ${ }^{4}$ El período que nos proponemos analizar en este trabajo, período de cambios sin un campo de experiencia al que poder asirse, produjo consecuentemente una marcada inseguridad que se plasmó en una gran variedad de significados en torno al campo semántico de religión.

Las aproximaciones a la cuestión religiosa en el seno del debate de 1869 no han tenido en cuenta hasta ahora que los debates, tanto en las Cortes como en los periódicos del momento, formaban parte de la lucha política por lo que era necesario analizar el significado de los conceptos manejados

\footnotetext{
4 Brelich 1989: vol. I, 93.
} 
para poder apreciar la modificación de los discursos dominantes. ${ }^{5}$ Tal y como afirma Francisco Díez de Velasco «es como si secularización equivaliese, en una especie de modelo evolucionista lineal bastante caricaturesco, a progreso, a madurez y plenitud del sistema social, a perfecta modernidad, camino gradual hacia la meta deseada que, en este caso, sería la total liberación de los modos religiosos de explicar y ordenar lo social y lo cultural». ${ }^{6}$ La actual historiografía ha tendido a analizar el tema de la libertad religiosa en clave de un rígido dualismo tradición/modernidad así como de una voluntad de encasillar a cada actor político en una de ellas, posturas ambas que en el fondo implican una visión teleológica. Sin embargo, no se puede establecer a priori el punto de llegada ni el curso hacia él; la modernidad no se identifica con un único modelo social o tipo ideal. Adoptar esa postura nos impide valorar en su justa medida el intenso debate que tuvieron que afrontar los intelectuales decimonónicos en su deseo de definir el concepto de libertad religiosa. Tradición/modernidad deben dejar de ser "contraconceptos asimétricos», en los cuales uno se define por oposición al otro, diseñando un universo cerrado, donde todo se deba clasificar como tradicional o moderno no dejando más alternativas posibles. ${ }^{7}$ La mutación conceptual no puede entenderse por el paso de unas ideas tradicionales a otras modernas, hay que analizar las torsiones de los sentidos en el interior del vocabulario preexistente.

Para llevar a cabo este estudio procederemos a analizar el campo semántico de "religión» (que incluirá conceptos relacionados como tolerancia/intolerancia o moral universal) para ver qué contenido le dieron los diferentes actores en juego y poder entender así qué tipo de libertad de cultos querían establecer y qué significado encerraba para cada publicista o grupo político. No partimos así pues del grupo político y de sus miembros para llegar al concepto sino que partiendo del concepto observaremos su utilización por los diferentes miembros de los grupos políticos: no nos interesa analizar en cuanto se aproximan los conceptos manejados a nuestra concepción actual de los mismos, pues estaríamos cayendo en un anacronismo, lo que nos interesa es conocer qué entendieron y cómo manejaron los conceptos los publicistas del momento. El período histórico analizado es muy concreto, desde el 11 de febrero de 1869, fecha de apertura de las Cortes Constituyentes, hasta el 5 de mayo de 1869, fecha en la que se votaron los artículos 20 y 21 que consagraron la libertad de cultos. Serán utilizadas como fuentes de estudio los Diarios de Sesiones de las Cortes $(D S C)^{8}$ y los principales periódicos de las diferentes tendencias políticas de la época. ${ }^{9}$

5 Tenemos diferentes aproximaciones a la cuestión religiosa, unas específicas del proceso constituyente de 1869 como las realizadas por Perlado 1970 o la de Petschen 1974, y otras más generales sobre determinadas cuestiones como anticlericalismo: Cruz 1997 y La Parra López y Suárez Cortina 1998; sobre libertad de conciencia: Souto Paz 1992, VV. AA. 2014 y las antes mencionadas de Llamazares Fernández y Barrero Ortega; sobre relaciones Iglesia-Estado o Iglesia-Sociedad: Aubert 2002, Callahan 1989, De Puelles Benítez 1986 y Hibbs-Lissorgues 1995.

6 Diez de Velasco 2012: 220.

7 Koselleck 1993: 205-250; González Manso 2015: 142-158.

8 Diario de Sesiones de las Cortes Constituyentes (en adelante DSC) 1870: tomo II y III.

9 El Pensamiento Español, diario católico, apostólico, romano, año X. 1869. Madrid: Imprenta Pelayo 34; La Iberia, periódico liberal, año XVII. 1869. Madrid: Imprenta de La Iberia; La Igualdad, diario republicano, año II. 1869. Madrid: Imprenta de La Igualdad; El Imparcial, diario liberal 1869. Madrid: Imprenta de El Imparcial.

\section{CONTEXTO RELIGIOSO}

Tras la muerte de Fernando VII en 1833, el paso de una monarquía absoluta a una monarquía liberal no solo supuso la transformación de la organización política del reino sino también la desaparición de instituciones esenciales para el orden jerárquico del siglo XVIII. La Iglesia tuvo que adaptarse a esta nueva realidad que le supuso la pérdida de la omnipresente función social y cultural que había tenido hasta el momento. A pesar de que la destrucción casi total de las órdenes religiosas masculinas en la década de 1830 afectó a las escuelas regidas por los regulares, las tres leyes fundamentales que rigieron la educación hasta 1868 (la Ley de Educación Primaria, 1838, y las Leyes de Instrucción Pública, 1845-1857) no pretendieron eliminar la religión de las escuelas estatales, al ser considerada piedra angular de la conducta civil y moral. El Concordato de 1851 y la Ley Moyano de 1857 reconocían el derecho general de la Iglesia a supervisar la educación. Entre 1857 y la Revolución de 1868 la Iglesia se esforzó en conseguir un mayor control de la educación ante el miedo de que desde las escuelas estatales se propagasen las ideas secularizadoras. La efímera ley Orovio de 1868 habría supuesto una fuerte intervención de clérigos y de religiosos en la instrucción pública. Pero la revolución derogó esta ley y a través del Decreto de 21 Octubre 1868 estableció la libertad de enseñanza.

Como apunta Manuel Suárez Cortina, a partir de la década de 1850 se estableció un nuevo tiempo político con respecto a la cuestión religiosa ${ }^{10}$ : por una parte, con la política del Vaticano de cerrar filas contra el liberalismo (baste recordar el Syllabus Errorum de 1864) junto a la aparición del neocatolicismo en España y, por otra, la petición de libertad religiosa y de cultos, enmarcada dentro de las libertades individuales, a partir de las Cortes Constituyentes de 1856 pero plasmada en las de 1869 . Es decir, por una parte los defensores de una apertura hacia un ideal más actual de vida cristiana y por otra la Iglesia española en una posición de apología y defensa a ultranza del viejo orden social y religioso. ${ }^{11}$ Pero, frente al catolicismo liberal desarrollado en Francia, Bélgica o Italia a partir de 1828 y basado en las obras de Lamennais en un principio y de Montalembert posteriormente, en España este fenómeno se mostró esquivo y con unas características muy particulares ${ }^{12}$ : "La unidad religiosa y la confesionalidad fueron elementos centrales a la propia concepción religiosa y política de los católicos liberales». ${ }^{13}$ Sin entrar en un análisis del desarrollo que tuvo el catolicismo liberal (o el liberalismo católico) en España, pues excede este trabajo, sí que podremos observar en las reflexiones de muchos políticos de diferente signo, desde antes del debate constituyente de 1869, unos intentos de conciliar sus ideas liberales con su sentido profundo de la religión católica cercanos, aunque con sus particularidades, a las defendidas por Lamennais en su obra Paroles d'un croyant publicada en $1834^{14}$ e inmediatamente traducida al español, italiano, inglés... ${ }^{15}$

10 Suárez Cortina 2014: 51.

11 Ibídem: 104.

12 Maravall 1972: 229-266.

13 Suárez Cortina 2014: 105.

14 Lamennais 1834a.

15 Ibídem 1834b. También tuvo gran difusión la traducción de J. de Larra de 1836 con prólogo del traductor. 
Paralelamente a estos intentos de conciliación de liberalismo y catolicismo se iban desarrollando posiciones extremas. Por una parte algunos autores como William Callahan ${ }^{16}$ o Antonio Moliner Prada observan cómo, desde mediados del siglo XIX, se fue produciendo una aceleración del proceso de descristianización, sobre todo en las grandes ciudades y en las zonas agrarias latifundistas, como consecuencia de la pérdida de influencia de la Iglesia entre las clases populares. ${ }^{17}$

Este proceso de descristianización fue acompañado, al final del reinado de Isabel II, del intento por parte del clero de aumentar su influencia en la esfera del poder civil, tal y como destaca Gregorio de la Fuente Monge: de hecho el clero fue el único baluarte con el que contó la reina desde 1863. Por ello los revolucionarios culparon a Isabel II de haber favorecido los intereses clericales llegando a convertir el régimen liberal en una dictadura teocrática. ${ }^{18}$ Los neocatólicos, defensores del papa, de los derechos y libertades de la Iglesia y de una teocracia intolerante, fueron adquiriendo influencia en la política palaciega y en la opinión nacional. ${ }^{19} \mathrm{El}$ cierre doctrinal y la centralización institucional protagonizada por la Iglesia junto con el apoyo del gobierno liberal español al servicio de una ortodoxia católica en regresión, dificultaron la difusión, que se estaba dando en Europa, de las posturas que defendían la separación e independencia de las instituciones estatales y eclesiásticas. $^{20}$

La Revolución de 1868 («La Gloriosa»), cuyo lema fue «iAbajo lo existente!», provocó una fuerte oleada de anticlericalismo de la que se hizo eco la prensa católica. Pero la violencia anticlerical no fue dirigida contra la fe o las creencias populares sino contra las estructuras eclesiásticas y además el grado varió según las juntas revolucionarias que se constituyeron. ${ }^{21}$ En realidad, tal y como apunta Antonio Moliner, la aplicación de las resoluciones anticlericales dependió en gran parte del talante de los gobernadores civiles y de sus buenas o malas relaciones con los obispos de sus diócesis. ${ }^{22}$

A partir de octubre 1868, el gobierno provisional adoptó una serie de medidas radicales contra la Iglesia: derogación del fuero eclesiástico, expulsión de los jesuitas, supresión de todas las órdenes religiosas y derribos de edificios religiosos (con fines urbanísticos o sociales según De la Fuente Monge). ${ }^{23}$ Pero no se produjeron, por lo general, ataques contra el clero: "la 'sacrílega piqueta revolucionaria' fue más secularizadora que anticlerical». ${ }^{24}$ Según este autor, las elites revolucionarias, para evitar una ruptura prematura de la coalición liberal (conformada por miembros de la Unión Liberal, Demócratas y Progresistas), solo identificaron como fuente visible de todos los males a Isabel II con lo que salvaron a la Iglesia de convertirse en objetivo prioritario de las protestas populares.

16 Callahan 1989: 234.

17 Moliner Prada 1998: 103.

18 De la Fuente Monge 2001: 127.

Alonso 2014: 219.

Ibídem: 230.

1 Moliner Prada 1998: 107.

22 Ibídem: 109.

23 De la Fuente Monge 2001: 132.

Ibídem: 136.
De diferente opinión es Manuel Revuelta para el cual muchas de las medidas anticlericales tomadas por el Gobierno, además de herir los sentimientos católicos, habrían ido en contra del ideario democrático proclamado: así la supresión de la Compañía de Jesús y de los conventos de religiosos habría ido en contra del derecho de reunión o el cierre de colegios de los jesuitas en contra de la libertad de enseñanza. Por ello considerará que el anticlericalismo del Sexenio habría sido un acicate para un catolicismo dormido pues se habría manifestado desde posiciones hostiles a la fe y considerado el cristianismo una lacra social. ${ }^{25}$ Disentimos completamente de esta opinión, tal y como mostraremos a continuación, pues las medidas anticlericales tomadas no implicaron, en la gran mayoría de los casos, un rechazo o un menosprecio de la religión católica.

En un clima de gran intolerancia por parte del clero y en particular del episcopado, con ataques violentos por parte de carlistas (como por ejemplo en Burgos contra el gobernador provincial) junto con muestras de anticlericalismo popular, se inició el debate constituyente, teniendo particular protagonismo la discusión de los artículos dedicados a la libertad de cultos. Los artículos propuestos decían lo siguiente: «Art. 20. La Nación se obliga a mantener el culto y los ministros de la religión católica»; «Art. 21. El ejercicio público o privado de cualquiera otro culto queda garantido a todos los extranjeros residentes en España, sin más limitaciones que las reglas universales de la moral y del derecho. Si algunos españoles profesaren otra religión que la católica, es aplicable a los mismos todo lo dispuesto en el párrafo anterior». Como reconoció la propia Comisión encargada de la elaboración del proyecto de Constitución, la cuestión religiosa fue la que más dificultades tuvo en su redacción pues de hecho los diputados tocaron muy frecuentemente cuestiones de dogma o discutieron más de religión que de la forma política a dar a la religión en España. Tres van a ser las principales posibilidades prospectadas por los políticos del momento para plasmar la de cultos: mantenimiento de la confesionalidad católica del Estado, establecimiento de la separación Iglesia/Estado y una acomodación a las exigencias de la realidad sociológica española y al espíritu de transacción. ¿Pero qué entendieron por religión/religiones para llevarles a establecer esos modelos de relación Iglesia/Estado?

\section{EL CONCEPTO DE RELIGIÓN}

Para la mayoría de los diputados liberales e incluso republicanos, la religión era una necesidad del ser humano. Es en su caracterización en lo que diferirán. Para algunos, el hombre es religioso por naturaleza por lo cual no se puede suprimir la religión de la vida social, no se pueden negar todos los cultos y todas las religiones como propuso el republicano Suñer. Si para De los Ríos Rosas, diputado de la Unión Liberal (UL), el sentimiento religioso estaba arraigado en el corazón humano, se encontraba «en la raíz, en la organización, en la necesidad de la vida humana» ${ }^{26}$, para el diputado progresista Mata «el sentimiento de la

\footnotetext{
25 Revuelta González 2002: 173.

26 De los Ríos Rosas, Antonio. DSC, T II, sesión de 9 de abril de 1869:
} 958. 
fe, el sentimiento de la veneración, esos dos elementos del sentimiento religioso, son innatos: los hombres son originariamente religiosos»; según el grado de desarrollo personal de ese sentimiento el hombre será muy religioso, medio o escéptico. "De todos modos, siempre es una verdad que ese sentimiento existe originariamente como ley de la organización del hombre, como un hecho propio de su especie». ${ }^{27}$

Pero si ese sentimiento en el fondo se debía a Dios, en la forma, en su manera de expresarse, es decir en el culto, sería un producto humano y así pues cultural:

Dónde quiera que vayáis, encontraréis siempre algún culto en esta o en aquella forma [...] pero así como no encontraréis pueblo alguno donde no haya alguna forma de culto, así también encontraréis siempre una infinidad de formas. Lo que pertenece al Creador, el fondo, siempre es igual: lo que pertenece al hombre, lo que pertenece a su inteligencia, a sus ideas, es variable. ${ }^{28}$

Para el demócrata Moret la religión era más que una ley moral, «representa las relaciones del hombre con la causa creadora, las relaciones del ser finito con el infinito, eso que es lo único que le levanta en la larga serie de desgracias que marcan sus huellas en la vida». ${ }^{29}$ Para este diputado, el hombre regido por una moral materialista podía no hacer el mal, pero no haría las grandes obras de entrega a las que solo se vería impulsado por el sentimiento religioso. Además el hombre no ilustrado solo poseería la religión para dar sentido a su vida: "así es que el hombre que vive del trabajo de cada día, esa inmensa masa del pueblo, no tiene más nociones que aquellas que le dio su religión: ella le ha enseñado lo que sabe de su origen y de su destino; ella le ha dicho algo sobre el origen del mundo; ella le ofrece una solución a todas las eternas dudas del inquieto espíritu». Según Moret se habría superado ya "el esnobismo» de valorar el escepticismo como símbolo de progreso dado que el hombre, ilustrado o no, necesitaba la religión:

En otros tiempos era ser liberal negar a Dios; era un progreso ser escéptico, era prueba de espíritu fuerte, burlarse de las creencias, que se relegaban al uso y al dominio de la gente vulgar y de los espíritus apocados. Pero ese tiempo pasó por fortuna, y el espíritu humano necesita algo más científico que las frivolidades de la enciclopedia, y en ese progreso, la religión lejos de alejarse, lejos de desaparecer, se extiende, se agranda al par que se depura, y uniéndose a todos los momentos de la vida humana. ${ }^{30}$

Para el diputado republicano Castelar hay personas «que no necesitan para nada del sentimiento religioso, que no necesitan de la idea religiosa para fundar la moral; pero esto no sucede en todos los caracteres" por lo cual la religión es necesaria en estos casos. No solo para la vida diaria sino sobre todo al final de la vida: "y que cuando tenemos los días contados, hace que levantemos nuestro

27 Mata y Fontanet, Pedro. DSC, T III, sesión de 3 de mayo de 1869: 1573.

28 Ídem.

29 Moret y Prendergast, Segismundo. DSC, T III, sesión de 4 de mayo de 1869: 1612 .

30 Ibídem: 1612-1613. espíritu a un mundo mejor, y que pensemos en la verdad absoluta, y elevemos nuestra inteligencia al amor infinito». ${ }^{31}$ Este diputado considerará necesaria para el ser humano la existencia de moral o de religión, es decir de algo a lo que poder agarrarse y que marque las pautas de la vida. En el caso de que sea una religión reivindicará la igualdad de todas las religiones en cuanto a su contenido y finalidad: «el paganismo, Sres. Diputados, no es esa mera colección de fábulas que se llama mitología y que aprenden los niños en la escuela. El paganismo es una religión con su dogma, con su moral, con sus principios, con sus grandes alternativas, con su gran teocracia, con su desarrollo muy semejante al desarrollo del catolicismo». ${ }^{32}$

Quien lleva a cabo el análisis del concepto religión de forma más «científica» e incluso diríamos no religiocéntrica será el diputado republicano Suñer. Este diputado, para defender sus principios ateos, se preguntará por el concepto de religión y planteará que no se puede tener ante la definición de este fenómeno una postura anacrónica y presentista. El constatar que este concepto ha variado a lo largo de los tiempos y de las culturas, le llevará a no considerar las religiones verdades eternas sino productos exclusivamente humanos. Partiendo de la definición del Diccionario de la Academia Española, dará una definición de religión general («lazo estrecho que une a la criatura con su Criador y que le infunde un sentimiento de amor, de respeto, de esperanza»), con la que buscará englobar mejor las creencias religiosas de todo tiempo y espacio, pero que le llevará a constatar que la definición ha cambiado a lo largo de los tiempos:

Yo podría ir recorriendo gran número de Religiones que se han conocido desde los tiempos históricos, y en todas esas Religiones iríamos observando que el concepto de las mismas se va modificando según las condiciones de los tiempos, según las circunstancias en que los hombres se hallan, en una palabra, según todas las condiciones a que se hallará probablemente sujeto el hombre en el camino de la vida. ${ }^{33}$

Ese carácter variable de las religiones, incluso con interpretaciones tan diferentes de la vida y de la muerte (para ello pondrá el ejemplo del budismo comparado con el catolicismo), le llevará a defender su carácter humano y así pues variable y prescindible.

\section{LA RELIGIÓN COMO VERDAD}

El punto de partida del clero y de los carlistas fue que la religión católica era la única verdadera y de aquí su exigencia de no permitir otros cultos. Así el magistral de Vitoria, Manterola afirmará:

Cuando estamos en posesión de la verdad revelada; cuando conocemos la verdad religiosa; cuando sabemos positiva y seguramente que la religión católica es eminentemente cierta, porque es la religión de Dios, y Dios es el autor de la religión y de la Sociedad, puesto

31 Castelar, Emilio. DSC, T II, sesión de 7 de abril de 1869: 901.

32 Castelar, Emilio. DSC, T III, sesión de 5 de mayo de 1869: 1642.

33 Suñer y Capdevila, Francisco. DSC, T III, sesión de 26 de abril de 1869: 1360-1361. 
que Dios no se pone nunca en contradicción consigo mismo, ¿no es triste, tristísimo, doloroso y amargo, y cruel para el corazón de los españoles, el que hoy en España pueda, ni por un solo momento, ponerse en duda la conveniencia y la necesidad de que nuestra Nación continúe siendo lo que hasta aquí, un pueblo exclusivamente católico ? $^{34}$

Desde las páginas del periódico neocatólico El Pensamiento Español se preguntarán cómo se podía discutir de si una religión merecía o no un privilegio especial, sin remontarse a los fundamentos de esa religión, sin entrar a analizar si eran verdaderas o falsas. ${ }^{35}$ Por ello para el arzobispo de Zaragoza «un católico, pues, no puede defender ni aprobar como bueno por sí misma la libertad de otros cultos, así como no puede defender ni aprobar la libertad de la blasfemia, del perjurio, del robo y del asesinato»; sería como reconocer «el derecho de insurrección contra la autoridad divina, lo que si en política es anárquico, en religión es impío». 36

El mundo liberal-demócrata, desde las páginas del periódico liberal progresista La lberia, reprochará a los neocatólicos el querer apropiarse de la religión al considerarse «únicos depositarios del arca santa de las creencias, piensan que ellos solos pueden salvar la fe religiosa de nuestros padres ${ }^{37}{ }^{37}$ Por su parte, desde el periódico republicano La lgualdad, considerarán que aceptar que una religión detenta la verdad absoluta supondría ir en contra de la razón: "(La verdad absoluta) o la recibimos sin examen, es decir, irracionalmente, en cuyo caso obramos contra la naturaleza, y destruyendo el hombre hacemos imposible toda religión, o la aceptamos después de un examen, en cuyo caso establecemos la libertad de cultos como un derecho natural». ${ }^{38}$

Para muchos de los diputados liberal-demócratarepublicanos, católicos o no, existían muchas verdades, tantas como religiones, por ello para el diputado progresista Aguirre «no he dicho que debía admitirse el error, sino que el que tiene una creencia es tan digno de respeto como el que tiene otra, porque si el católico creía que su religión era la verdadera, el protestante cree lo mismo». ${ }^{39}$ En el mismo sentido se expresará el republicano Castelar añadiendo además el peligro que entrañaba que una religión creyese detentar la verdad, "Con este pensamiento ¿no se han justificado los crímenes de todas las teocracias? ». ${ }^{40} \mathrm{Y}$ ya más específicamente referido a la religión católica, el también republicano Pi y Margall arremeterá contra su pretensión de detentar la verdad a pesar de que «¿Ha habido una religión que haya tenido una serie tan interminable de herejías como la religión cristiana? ¿Y pretendéis que la religión cristiana sea la mayor de las verdades? Si sus principios fuesen tan verdaderos como los de que antes he hablado,

34 De Manterola y Pérez, Vicente (magistral de Vitoria). DSC, T III, sesión de 26 de abril de 1869: 1382.

35 «Una sesión impía». El Pensamiento, 27 de abril de 1869.

36 «A las Cortes Constituyentes» de Fr. Manuel, arzobispo de Zaragoza. El Pensamiento, 3 de abril de 1869.

37 Política: «Los enemigos de la situación». La Iberia, 28 de marzo de 1869.

38 «La libertad de cultos es de derecho natural II». La Igualdad, 20 de abril de 1869 .

39 Aguirre, Joaquín. DSC, T III, sesión de 28 de abril de 1869: 1432.

40 Castelar, Emilio. DSC, T III, sesión de 5 mayo de 1869: 1640. la humanidad entera los hubiera aceptado desde el primer día, y hoy no encontraríamos argumento ninguno para combatirla». ${ }^{41}$

\section{LA RELIGIÓN COMO ASUNTO PRIVADO}

Aunque la religión católica no excluye una comunicación entre el hombre y Dios que permitiría alcanzar, tal y como afirma el diputado de la UL Álvarez Bugallal, «una solución de las grandes cuestiones que interesan al hombre con relación a la Divinidad, a sí mismo, a su fin temporal y a su fin último ${ }^{42}$, esta comunicación no alcanzaría el rasgo de exclusivismo que defenderán los republicanos.

Los diputados republicanos no ateos insistirán en su definición de religión como relación entre Dios y el hombre, sin protagonismo de la Iglesia, una relación alejada de todo boato y demostraciones externas. Aquellos diputados que no se declaran claramente ateos (y en este caso para ellos subintraría de manera exclusiva la moral, como veremos a continuación), considerarán que la religión sería necesaria pero sin una institución que la controle e intente imponer sus pautas morales a toda la sociedad. El problema es la Iglesia, no el sentimiento religioso. Es el mismo problema con el que se encontraron los liberales de $1812^{43}$ : si en aquel momento no se plantearon dejar fuera a la Iglesia del edificio político en construcción (reformándola previamente, eso sí), en estos momentos parte de los intelectuales sí se plantean una ruptura más neta con la institución eclesiástica, no con el sentimiento religioso. Por ello, los republicanos, al reconocer otros cultos, además de defender un derecho natural, conseguirían diluir la influencia perniciosa de la Iglesia católica. Para el diputado republicano García Ruíz el dios del catolicismo, del protestantismo, de los musulmanes o de los judíos sería el mismo y la religión debería entenderse como un asunto privado, "la religión es un asunto entre el hombre y Dios». ${ }^{44}$ En realidad están igualando religión y religiosidad; para ellos solo existe la religiosidad personal de cada individuo negando así el carácter social de la religión. Así Castelar afirmará "y como la religión, después de todo, no es tanto una relación social como una relación del hombre con Dios, podréis engañar con la religión impuesta por el Estado a los demás hombres, pero no engañareis jamás a Dios, a Dios, que escudriña con su mirada el abismo de la conciencia». ${ }^{45}$ Con su insistencia en el carácter íntimo del sentimiento religioso, en cierta manera, los republicanos están al borde de negar la práctica cultual pública que en teoría defienden. Así de contundente se manifestará en este sentido el periódico La lgualdad: "Nosotros detestamos todo signo exterior, todo enmascaramiento, todo ruido que nos estorbe, porque repito que no creemos más que en Dios en espíritu y en verdad, pero toleramos (porque así lo creemos necesario) hasta el ruido de la campana vecina que no es por cierto muy conducente ni muy halagüeño para adorar a Dios». ${ }^{46}$

41 Pi y Margall, Francisco. DSC, T III, sesión de 3 mayo de 1869: 1566.

42 Álvarez Bugallal, Saturnino. DSC, T III, sesión de 3 de mayo de 1869: 1578.

43 González Manso 2014: 120.

44 García Ruíz, Eugenio. DSC, T III, sesión de 26 abril de 1869: 1365.

45 Castelar, Emilio. DSC, T II, sesión de 12 abril de 1869: 988.

46 «Comentario». La lgualdad, 18 de abril de 1869. 
Diferente posición será defendida desde el mundo liberal y que explicará en parte su posicionamiento en cuanto a los artículos «librecultistas». Así el diputado Ulloa, de la UL, introducirá el carácter social de la religión; ésta no puede ser considerada un hecho individual entre Dios y el hombre como pretenden los republicanos. La religión tiene que traducirse en manifestaciones, tiene que tener un dogma y ser regulada por una institución; la Iglesia «no es sólo de creer en tal o cual religión, sino de poder tener culto y de expresar ese culto y de manifestar ese culto». Y como hecho social que es tendría que estar bajo el control «de los poderes sociales en todas aquellas relaciones (que) sostiene el Estado con la Iglesia». ${ }^{47}$ De aquí uno de los motivos para no considerar oportuna una separación neta Iglesia/ Estado. Su papel social es tal que, como apunta el diputado progresista Rojo Arias, la religión ayudaría a conformar las costumbres de un país. ${ }^{48}$

\section{RELACIÓN ENTRE RELIGIÓN Y RAZÓN}

Las dos posturas extremas las representan los neocatólicos y el clero, para los cuales la religión es fe, mientras que para los republicanos la religión solo puede entenderse a través de la razón. En posiciones intermedias tenemos las posturas de los demás grupos, que oscilan desde un mayor o menor protagonismo de la fe hasta aquellos que no excluyen la razón para entender la religión.

Para el obispo de Santiago el hombre no puede, amparándose en la razón, elegir una religión puesto que solo existe una verdadera: «el hombre no tiene derecho a profesar la religión que quiera: el hombre tiene obligación a profesar la religión verdadera». ${ }^{49}$

Para algún diputado liberal católico la razón tampoco puede ser la base de la religión pues ésta trata de verdades fundamentales y la razón comete fallos: «el Autor de lo creado [...] lo que hizo fue poner fuera de discusión, fuera del embate de la razón humana, fuera de esas vacilaciones constantes y de esos desmayos a que la razón es ocasionada, las verdades eternas». ${ }^{50}$ En el mismo sentido para el diputado progresista Montesino la verdad religiosa no se puede demostrar y la fe constituye una parte esencial de la misma. ${ }^{51}$

Los principales defensores de acercarse a la religión a través de la razón serán los republicanos, católicos o no. Para Castelar el hombre no puede renegar de su razón e inteligencia puesto que son productos dados al hombre por Dios y no puede verlos como inferiores a otros misterios de la obra divina. Estos rasgos le han permitido alcanzar los logros, entre otros, de los derechos individuales: "los derechos individuales, las leyes de nuestra naturaleza, las leyes de nuestra organización, las leyes de nuestra voluntad, las leyes de nuestra conciencia, las leyes de nuestro espíritu, son otra mecánica celeste no menos grande, y muestran

\footnotetext{
47 Ulloa, Augusto. DSC, T III, sesión de 26 abril de 1869: 1371.

48 Rojo Arias, Ignacio. DSC, T III, sesión de 4 mayo de 1869: 1600.

49 García Cuesta, Miguel (obispo de Santiago). DSC, T III, sesión de 27 abril de 1869: 1412.

50 Álvarez Bugallal, Saturnino. DSC, T III, sesión de 4 de mayo de 1869: 1590.

51 Montesino, Cipriano Segundo. DSC, T III, sesión de 29 abril de 1869: 1471.
}

que la mano de Dios ha tocado a la frente de este pobre ser humano y lo ha hecho a Dios semejante».52

Pi y Margall considerará que a Dios solo se le puede intentar conocer a través de la razón lo cual no quiere decir negar la existencia de Dios:

En lenguaje filosófico decir que Dios es una especie de creación da la razón humana, no significa sino que, prescindiendo de la existencia o no existencia de ese Ser, nosotros no comprendemos su existencia sino por un esfuerzo de nuestra razón [...] Se llama ateo al que niega sistemáticamente la existencia de Dios; y yo, lejos de eso, dije que Dios era una incógnita que la humanidad no llegará nunca a descubrir. Que Dios es indemostrable, creo que es cosa que admiten todas las escuelas..$^{53}$

\section{RELACIÓN ENTRE RELIGIÓN Y MORAL}

Uno de los conceptos que compitió con el de religión fue el de moral universal. Este concepto será defendido en algunos casos como sustitutivo y en otros como complementario al de religión. La moral serviría de contrapeso para moderar los posibles desmanes sociales a falta de una religión. Ante los problemas que planteaba el catolicismo por culpa de sus aspectos institucionales, el mundo republicano, principalmente, abogará por dar un mayor protagonismo a la moral universal como elemento regulador de las sociedades.

Para el mundo carlista y clerical, pretender sustituir la religión católica por el freno de la moral universal sería un peligro pues «no son regla segura, porque la moral universal, independiente de la idea religiosa, es una utopía» ${ }^{54}$ y "la moral se asienta en la religión». ${ }^{55}$ Para Antolín Monescillo, obispo de Jaén, el papel que se le quería hacer jugar a la moral universal entrañaba el problema de la indefinición que conllevaba, además de ser inútil desde el momento que existía la religión católica: «¿Para qué apelar a la moral universal teniendo la moral católica?». ${ }^{56}$

El mundo liberal católico pondrá en cambio el acento, en clave ilustrada, en que solo las personas instruidas podrían alcanzar el concepto de moral pero el pueblo no; para éste solo quedaría la moral católica. ${ }^{57}$ Y la moral, católica o no, era imprescindible para mantener el orden social.

Visión diferente tendrá el mundo republicano. Para Castelar, moral y religión, además de actuar a través de la razón, tendrían las mismas funciones y aportarían las mismas soluciones a los problemas del ser humano, incluso en fin de vida: «¿Y qué hace la religión? Lo mismo que hace la moral [...] y al acercarnos a la última hora, al acercarnos al abismo de la eternidad, sostenernos y consolarnos». ${ }^{58}$ Pero para este diputado, ante la situación de indiferentismo al que habría llevado a la sociedad la Iglesia católica, solo la moral universal podría salvar al mundo del estado de crisis en el que se encontraba: «Esta grande crisis, esta crisis moral sería espantosa si no tuviéramos un principio [...] (Por el

52 Castelar, Emilio. DSC, T II, sesión de 12 abril de 1869: 990.

53 Pi y Margall, Francisco. DSC, T III, sesión de 4 mayo de 1869: 1588.

54 «Comentario». El Pensamiento, 13 de abril de 1869.

55 «Cortes Constituyentes». El Pensamiento, 14 de abril de 1869.

56 Ibídem: 15 de abril de 1869.

57 Ulloa, Augusto. DSC, T III, sesión de 26 abril de 1869: 1372.

58 Castelar, Emilio. DSC, T III, sesión de 5 mayo de 1869: 1640-1641. 
cual) todos los hombres practiquen los principios de eterna moral que están grabados en el fondo de la conciencia humana». ${ }^{59}$ Incluso para Suñer ser ateo no significaría no tener moral pero sería una moral humana, racional: «Es un error, y un error grande, el creer que los materialistas estamos reñidos con la moral: somos morales, queremos la moral, y el último fin de nuestras predicaciones es la moral, pero la moral independiente, la moral humana y nacida del corazón humano, no la que nace de la noción de Dios». ${ }^{60}$ Por ello estaríamos de acuerdo con la opinión de José Álvarez Junco sobre las «dosis de moralidad y de actitudes cristianas» de los anticlericales frente a la de Revuelta González que relaciona los «niveles de anticlericalismo» con el ateísmo. ${ }^{61}$ Es importante recordar que anticlericalismo no significa irreligiosidad.

\section{El Ateísmo}

El discurso del diputado Suñer y Capdevila el 26 de abril de 1869 suscitó una enorme polémica en la Cámara (no terminará su discurso abandonando la sala él y los diputados republicanos para volver al cabo de unas horas) pero también en la calle. Suñer defenderá su postura contra las religiones como un elemento de progreso: «La idea caduca es la fe, el cielo, Dios. La idea nueva es la ciencia, la tierra, el hombre». ${ }^{62}$ Acabar con el protagonismo de la religión en la vida de la sociedad permitiría además enlazar con los demás países europeos de los que nos manteníamos separados desde la Edad Media por culpa de la actuación de la Iglesia. "La última parte de esa enmienda explica bien a las claras que yo desearía que los españoles no profesaran ninguna religión». La religión separa al hombre de los problemas reales de la sociedad impidiéndole tomar las decisiones necesarias para afianzar el progreso: «hubiera indicado que uno de los gravísimos males que tienen las Religiones todas es el de que son tristes, que nos hacen separar los ojos de la tierra para dirigirlos al cielo, contemplando eternamente esta vida de delicias que es un bello sueño, pero que por ser sólo un sueño, es necesario despertar de él». ${ }^{63}$

El discurso de Suñer suscitará una rápida respuesta de los miembros del gobierno, como la del progresista Mata, que considerarán que ese discurso respondía a una opinión personal del diputado republicano y no reflejaría el sentir de los españoles. La Comisión, en palabras de Mata:

No puede aceptar la enmienda del Sr. Suñer y Capdevila porque es la más incompatible con el texto del proyecto. Todas las demás enmiendas, al fin y al cabo, ora defiendan la unidad de la religión católica, ora procuren dar más ensanche al ejercicio de los demás cultos, todas contienen algo que se relaciona con el texto enmendado; todas contienen la afirmación del culto, mientras que la enmienda del Sr. Suñer, en lo que

\footnotetext{
59 Castelar, Emilio. DSC, T II, sesión de 7 abril de 1869: 900.

60 Suñer y Capdevila, Francisco. DSC, T III, sesión de 4 mayo de 1869: 1598.

61 Álvarez Junco 1985: 284; Revuelta González 1999: 12-13.

62 Suñer y Capdevila, Francisco. DSC, T III, sesión de 26 abril de 1869: 1360.

63 Suñer y Capdevila, Francisco. DSC, T III, sesión de 4 mayo de 1869: 1597.
}

atañe a su segundo extremo, es la negación de todo culto; tiende a la proclamación del ateísmo. ${ }^{64}$

La Iberia protestará ante el discurso de Suñer en las Cortes: «¿Pues qué, la libertad está reñida con el catolicismo? Pues qué, ¿la bandera la República puede disculpar esos funestos extravíos? No, y mil veces no" ${ }^{65}$ y afirmará que los demás periódicos también se habrían manifestado en contra excepto el periódico republicano La Igualdad. ${ }^{66}$ Aunque el ateísmo y el agnosticismo circulaban ya como ideas entre los intelectuales, hasta el momento no se habían producido manifestaciones públicas y en sede parlamentaria, de tal contundencia y con una finalidad política práctica. La sociedad en general no estaba preparada todavía para ver plasmado el ateísmo en una Constitución.

Más drásticos serán los periódicos neo-católicos. En los comentarios a los discursos de los diputados en las Cortes destacarán las fuertísimas críticas a las palabras de los diputados republicanos, en particular de Suñer que motivó numerosas convocatorias de funciones de desagravio a Dios y a la Virgen en numerosas iglesias de toda España por las «blasfemias proferidas en el Congreso de los Diputados». Tampoco quedaron sin respuesta las afirmaciones de $\mathrm{Pi} \mathrm{y}$ Margall contra las que arremetió El Pensamiento:

En cambio el Sr. Pi crea otro dios a su imagen y semejanza; un dios, por decirlo así, casero, inferior a la razón humana; como que, según el $\mathrm{Sr}$. $\mathrm{Pi}$, ese dios es hijo de la razón humana ¡Dios naciendo de la razón del hombre! [...] ¿Podría imaginar nadie cosa más absurda y más contraria al sentido común? [...] El Sr. Pi y Margall es ateo; pero tiene sin duda vergüenza de confesarlo, porque el ateísmo es la última palabra de la ignorancia, y se divierte en crear un dios estúpido que ni puede, ni sabe, ni quiere nada; un dios, en fin, creado por la razón humana. ${ }^{67}$

Es tal la ofensa que consideran habría recibido el catolicismo, que el grupo carlista el 5 de mayo de 1869 pedirá a las Cortes "se sirvan declarar que han oído con profundo sentimiento las manifestaciones anti-católicas hechas durante la discusión de los artículos 20 y 21 del proyecto de Constitución». ${ }^{68}$

\section{EL INDIFERENTISMO}

Uno de los motivos que darán los diputados liberaldemócratas para defender la aprobación de los artículos a favor de la libertad de cultos será la situación de indiferentismo religioso en el que se encontraba España y de la que hacían responsables a la Iglesia católica. Para ellos la única solución pasaría por permitir la presencia de varios cultos entre los cuales el ciudadano español pudiese, en función de su conciencia, elegir. Los republicanos, por su parte, no solo verán indiferentismo sino que, guiados probablemente más por un deseo que por una observación

64 Mata y Fontanet, Pedro. DSC, T III, sesión de 26 abril de 1869: 1362.

65 «Comentario». La Iberia, 27 de abril de 1869.

66 Ibídem: 28 de abril de 1869.

67 «El Discurso del Sr. Pi y Margall». El Pensamiento, 4 de mayo de 1869

68 Grupo carlista. DSC, T III, sesión de 5 mayo de 1869: 1629. 
de la realidad, muerte total del catolicismo. Aprobar la presencia de más cultos o no aprobar ninguno, en el fondo, para alguno de ellos era indiferente. Por su parte, y en una argumentación totalmente opuesta, el mundo clerical acusará a la libertad de cultos de provocar indiferentismo.

Para el diputado demócrata Godínez de Paz la exclusividad de una religión conduciría al indiferentismo y por ello el catolicismo estaría mostrando signos en España de falta de actividad y enfriamiento de los fieles. ${ }^{69}$ Para estos diputados el indiferentismo supondría un gran peligro para el ser humano como para la sociedad. ${ }^{70}$

Más contundentes serán los diputados republicanos. Para Castelar los españoles no habrían elegido su religión, eran católicos por tradición incluso en muchos casos en contra de sus propios sentimientos religiosos: «Hemos nacido bajo la influencia de una religión que ninguno de nosotros ha elegido; la aceptamos más tarde; la aceptamos por sentimiento, la aceptamos por conciencia, la aceptamos por nuestra familia, por nuestros hermanos, por nuestras madres; no nos atrevemos a descubrir en nuestra casa el fondo de nuestra conciencia». ${ }^{71}$ Por ello en muchos casos los católicos lo eran solo de fachada y su indiferentismo oculto les llevaba a muestras exageradas para mostrar lo buenos católicos que eran:

La indiferencia va aunada al fanatismo, y así es muy común ver a aquellos que no cumplen en poco ni en mucho las prácticas del culto católico, que escandalizan a la sociedad con su inmoral conducta y escandalosos vicios, exasperarse, gritar, encolerizarse y ponerse hasta frenéticos en cuanto alguno piensa, medita, escribe o habla en sentido contrario al de la religión que dicen profesar. $^{72}$

\section{Por ello para el periódico La Igualdad:}

Es más honroso, más digno y más apreciable declararse francamente ateo, negar a Dios, probarlo y combatir el error, que no darla de católicos fervientes [...] Nosotros, antes que estar conformes con los hipócritas autores de tales protestas preferiríamos ser ateos, y cuenta que no lo somos, por más que respetemos al que prescinde de la idea religiosa, que en último caso no demuestra otra cosa sino que es esencialmente materialista y partidario de la moral independiente. ${ }^{73}$

Pero para Pi y Margall, el catolicismo llevaría mucho tiempo muerto en España: «Poned a este pueblo entre su religión y su interés, y optará siempre por su interés, posponiendo siempre la religión [...] No hay, pues, temor ninguno; podéis hacer todo lo que queráis con la libertad religiosa sin el menor peligro de que se subleve la Nación». ${ }^{74}$ El catolicismo que se observaba era solo de fachada, "¿Sabéis lo que tenemos del catolicismo? Las prácticas, la rutina, los hábitos: no la fe, no el sentimiento religioso»; la realidad era que «el catolicismo ha muerto en la conciencia de la

69 Godínez de Paz, Carlos. DSC, T III, sesión de 29 abril de 1869: 1457.

70 «Vacilaciones conservadoras». El Imparcial, 16 de abril de 1869.

71 Castelar, Emilio. DSC, T II, sesión de 7 abril de 1869: 899.

72 «Crónica parlamentaria». La Igualdad, 28 de abril de 1869.

3 «Comentario». La Igualdad, 29 de abril de 1869.

74 Pi y Margall, Francisco. DSC, T II, sesión de 24 marzo de 1869: humanidad y en la conciencia del pueblo español». ${ }^{75}$ Por ello Pi no creía que en España existiese una unidad católica pues el catolicismo ya no tenía fuerza, estaba dividido. ${ }^{76} \mathrm{Y}$ la culpa de esta situación la tendría la Iglesia que se habría apartado de su mensaje original aferrándose a sus riquezas. Así para el diputado Garrido:

Lo que yo veo es que la mayor parte de los cristianos no perdonan medio ninguno para adquirir fortuna, siendo así que la fortuna en este mundo es incompatible con la bienaventuranza en el otro [...] No, el catolicismo está hundido y han sido los católicos y ha sido el clero católico los que lo han hundido. El clero es el que se ha separado de la religión y de las doctrinas de Jesucristo. ${ }^{77}$

Este diputado llegará incluso a afirmar que España se había convertido en una de las naciones menos católicas de Europa pues, según él, esta creencia no incidía ya en la conducta, en la vida privada y en las relaciones sociales y políticas de sus habitantes. ${ }^{78}$ Por ello, para él y otros diputados republicanos, al establecerse la libertad de cultos no se estaría yendo en contra del sentir del pueblo español, no habría incompatibilidad sociológica.

Argumentación totalmente opuesta presentará el mundo clerical y carlista. Para ellos permitir diferentes cultos, dar igualdad a todas las religiones, conducirá al indiferentismo y a sustituir la moral católica por la moral universal. ${ }^{79}$ ¿Y por qué se caería en el indiferentismo? Para el obispo de Astorga porque «el hombre que contempla tanta diversidad de doctrinas, tanta confusión de ideas, tanta absurdidad de ceremonias en la comparación continua de las sectas, enferma de languidez en su espíritu, y acaba por no adorar a su Dios bajo ninguna forma, durmiéndose, para siempre a caso, entre las sombras de la muerte». ${ }^{80}$ Por ello Monescillo, obispo de Jaén, no comprenderá «la variedad de Religiones; si todas son iguales, no hay ninguna religión [...] pluralidad de Dioses, nulidad de Dioses; a pluralidad de Religiones, nulidad de Religiones $"{ }^{81}$ Además el diputado Ortiz de Zárate advertirá que en las naciones donde existía la libertad de cultos era mayor el indiferentismo religioso. ${ }^{82}$

Para el diputado Díaz Caneja el catolicismo, entre todas las religiones, era el único adalid contra el indiferentismo y a favor de los sentimientos religiosos:

Hoy la ciencia que se llama positiva se reviste de un carácter ateo; ¿dónde está la defensa de la existencia de Dios hecha por los judíos? Hoy la ciencia que se llama crítica se reviste de un carácter anticristiano; ¿dónde está la apología del cristianismo por los protestantes? Sólo el clero y los creyentes católicos son los que sostienen tremenda lucha contra la incredulidad. ${ }^{83}$

75 Pi y Margall, Francisco. DSC, T III, sesión de 3 mayo de 1869: 1568.

76 Pi y Margall, Francisco. DSC, T III, sesión de 4 mayo de 1869: 1589.

77 Garrido y Tortosa, Fernando. DSC, T III, sesión de 4 mayo de 1869: 1606.

78 Ibídem: 1605

79 «La Peor solución». El Pensamiento, 31 de marzo de 1869.

80 «A las Cortes» del obispo de Astorga el 22 de abril de 1869. El Pensamiento, 1 de mayo de 1869.

81 «Cortes Constituyentes». El Pensamiento, 14 de abril de 1869.

82 Ortiz de Zárate, Ramón. DSC, T III, 28 abril de 1869: 1438.

83 Díaz Caneja, Domingo. DSC, T III, sesión de 4 mayo de 1869: 1623. 


\section{LA CUESTIÓN TOLERANCIA/INTOLERANCIA}

La tolerancia no debe ser contemplada sin más como el antecedente de la libertad religiosa: las raíces de ambas son diferentes. Como concepto histórico es dinámico y sometido a profundas transformaciones en virtud de cada contexto concreto de discusión. Así quedó patente durante el debate sobre la libertad de cultos.

Esta cuestión se planteará de forma dicotómica: para el mundo liberal-demócrata-republicano, tolerancia significaría aprobar la libertad de cultos mientras que intolerancia significaría exclusivismo religioso. Para el mundo clerical, en cambio, la tolerancia de la Iglesia habría sido una constante en su historia por lo que no sería necesaria la libertad de cultos.

Para poder defender la protección de la Iglesia católica actual recogida en los artículos, el Gobierno recurrirá a dos argumentaciones: reivindicar el pasado liberal de la Iglesia e introducir el relativismo histórico en cuanto al concepto de intolerancia: ésta habría dependido de las circunstancias históricas. La tolerancia habría nacido del «progreso general de la civilización y de la blandura y suavidad de las costumbres que han venido con la civilización misma» ${ }^{84}$ : todas las religiones en su pasado habrían sido intolerantes. Por ello, para estos diputados el permitir la libertad de cultos sería un síntoma de progreso.

La posición del mundo republicano será más compleja. Por una parte, los católicos necesitarán salvar la religión, que no la institución eclesiástica, y para ello recurrirán al mismo tipo de argumentación, vista previamente, de considerar que la Iglesia primitiva y medieval fue tolerante (al permitir la coexistencia de las tres religiones); esta situación habría cambiado al corromperse la Iglesia por exceso de poder: «nace tolerante y se hace intolerante [...] (Era tolerante) cuando la Iglesia era dominada, y sin embargo de proclamar la intolerancia cuando es dominadora, se vuelve intolerante y comete los mayores horrores que se han cometido en el mundo». ${ }^{85}$

Por otra parte los republicanos aplicarán el término intolerante no solo a los neocatólicos sino también a los liberales moderados por no atreverse a llevar a las últimas consecuencias la libertad de cultos: serían intolerantes pues no dejaban pensar a cada uno por sí mismo. ${ }^{86}$

En términos completamente diferentes se planteará el mundo clerical y carlista el concepto de tolerancia. «¿Si en España todos son católicos donde está la intolerancia?» se preguntarán desde las páginas de El Pensamiento. ${ }^{87} \mathrm{El}$ que no es católico "es porque no profesa religión alguna, y éstos, ¿no tienen la libertad que necesitan?». ${ }^{88}$ Puesto que existe la tolerancia necesaria a las características religiosas del país, ¿qué necesidad habría, se preguntará el obispo de Santiago, de romper la unidad católica? Diferente sería si en España coexistiesen ya muchas religiones como en otros países como Francia: en ese caso hipotético podría

${ }^{84}$ Valera Alcalá-Galiano, Juan. DSC, T III, sesión de 29 abril de 1869: 1477.

85 García Ruiz, Eugenio. DSC, T III, sesión de 26 abril de 1869: 1364.

86 «Comentario». La lqualdad, 29 de abril de 1869.

87 «La Tiranía y el despotismo en Religión». El Pensamiento, 29 de marzo de 1869.

88 «A las Cortes Constituyentes». El Pensamiento, 6 de abril de 1869. considerarse la libertad de cultos. ${ }^{89}$ Para el mundo clerical la existencia de tolerancia (que permite el culto privado pero no el público) haría innecesaria la libertad de cultos. Dos serían así pues los motivos para no establecerla: España era toda ella católica (y los españoles que no lo fuesen sería porque no tenían ninguna religión) y a los extranjeros se les permitía el culto privado. Por ello el diputado Ochoa considerará que:

Basta que se consigne el hecho de que la religión católica apostólica romana es la religión de la Nación española y con que no se moleste ni perturbe a esos individuos [...] no se puede perseguir a ningún español que quiera dar a su modo culto a Dios en el seno de su casa; no se puede perseguir a ningún español que, encerrado en su hogar, levante su corazón a Dios, con su familia, y le adore en la forma que lo creyese conveniente, y no se perseguiría con mi enmienda a ningún español..$^{90}$

¿Era la religión católica intolerante? Manterola diferenciará entre intolerancia contra el error y tolerancia contra quien yerre: "una cosa es la intolerancia con las doctrinas erróneas, la intolerancia que está en la naturaleza de las cosas, y otra la tolerancia con las personas que tienen la desgracia de errar $"{ }^{91}$ Ochoa introducirá, como el mundo liberal, la idea del relativismo para juzgar la intolerancia pero con un matiz: fue el poder civil, el intolerante, pero se debe de comprender dadas las circunstancias históricas. ${ }^{92}$

\section{LIBERTAD DE CULTOS, ¿SíMBOLO DE PROGRESO?}

Para algunos de estos diputados la religión católica, entendida en cuanto a su mensaje original, habría sido fuente de progreso para la civilización europea. Así para el diputado Valera de UL:

Desde la aceptación del cristianismo indudablemente hay una fuerza poderosa en la raza europea para sobreponerse a las demás razas de la tierra, y realizar el progreso en el mundo y llevar la civilización hasta el más alto grado de adelanto que cabe en lo humano [...] que la religión cristiana ha sido la religión más progresiva y más grande que puede concebirse: el venga a nos él tu reino, no es solamente para la otra vida, sino para esta que vivimos. Tal es la belleza de nuestra religión y tal su disposición para el progreso humano. ${ }^{93}$

Para los no republicanos y católicos, libertad y catolicismo no estarían reñidos, uno podía implicar el otro. De hecho con frecuencia se utilizó el argumento de que la libertad religiosa se deducía directamente de los Evangelios:

Somos liberales, porque somos católicos; somos católicos, porque creemos que sólo a la sombra de la libertad pueden saborearse los beneficios de una religión de caridad y amor [...] ambas prácticas se hermanan

89 García Cuesta, Miguel (obispo de Santiago). DSC, T III, sesión de 27 abril de 1869: 1409.

90 Ochoa de Olza, Joaquín. DSC, T III, sesión de 29 abril de 1869: 1451.

91 De Manterola y Pérez, Vicente. DSC, T III, sesión de 27 abril de 1869: 1397.

92 Ochoa de Olza, Joaquín. DSC, T III, sesión de 29 abril de 1869: 1450.

93 Valera Alcalá-Galiano, Juan. DSC, T III, sesión de 29 abril de 1869: 1475-1476. 
perfectamente, porque de una misma fuente proceden, porque su misión es la de instruir, educar, en una palabra, civilizar al pueblo. ${ }^{94}$

Y es en nombre de ese catolicismo que estos diputados proclaman la libertad de cultos. El problema para muchos de ellos es la Iglesia católica en cuanto institución; por ello, y al igual que hicieron los primeros liberales en los inicios de siglo XIX, muchos de estos diputados recurrirán a la reivindicación de la Iglesia primitiva, adalid de valores "liberales y democráticos» frente a la actual Iglesia corrupta por su afán de poder y dinero e interesada solo en los intereses terrenales. ${ }^{95}$ De hecho para el republicano Castelar, por culpa de la Iglesia como institución, el catolicismo habría sido y era contrario a todo lo que significase progreso en todas las facetas de la vida:

No hay un principio, absolutamente ninguno, que constituya la ciencia, aunque sea la base del derecho moderno, que no haya sido maldecido por la Iglesia católica; la Iglesia católica maldijo la reforma, y sin embargo, la reforma es hoy la base del derecho político en casi todo el mundo; la Iglesia maldijo también el sistema político de Inglaterra, y sin embargo, este sistema es la gran escuela, la gran enseñanza en que todos los hombres eminentes de Europa aprenden hoy los rudimentos y las prácticas constitucionales; la Iglesia maldijo la ciencia, toda la ciencia filosófica, y sin embargo, esta ciencia filosófica, que es método de Descartes, que son los tratados de Kant, la gran síntesis de Negely, las armonías de Krausse, es la ciencia que consultamos, y que leemos hoy más que la Biblia y que el Evangelio. ${ }^{96}$

Para el mundo clerical y carlista, el establecer la libertad de cultos supondría un retroceso en la senda del progreso y más grave, la destrucción del catolicismo disfrazada de tolerancia, de deberes internacionales o de interés del comercio. Esta libertad supondría crear una situación de desigualdad negativa para el catolicismo frente a las otras religiones además de abrir la «veda» contra los católicos. En una interpretación apocalíptica, la coexistencia de varias religiones traería, según ellos, el caos y el desorden total de la sociedad y del Estado pudiendo llegar a provocar la caída del mismo: «¿ ¿...] cómo vais a hacer que se perpetúe el Estado, el edificio que sobre esa base habíase levantado? Yo encuentro perfectamente lógico [...] que el hombre que deje de temer a Dios, se emancipe ya de toda autoridad humana [...] (y se rebele) contra toda autoridad, contra todo orden, contra toda superioridad $\gg .{ }^{97}$

\section{A MODO DE CONCLUSIÓN}

En los períodos de grandes cambios, cuando el campo de experiencia de los actores no abarca todas las nuevas posibilidades en juego, el significado atribuido por éstos a los conceptos cobra gran importancia para acercarnos a una mejor comprensión de las posturas y argumentos defendidos en un debate político. A lo largo de este trabajo hemos observado los diferentes significados atribuidos al

94 «Política». La Iberia, 5 de mayo de 1869.

95 Gil Sanz, Álvaro. DSC, T II, sesión de 6 abril de 1869: 860-861.

96 Castelar, Emilio. DSC, T II, sesión de 7 abril de 1869: 899.

97 De Manterola y Pérez, Vicente. DSC, T III, sesión de 26 abril 1869: 1383. concepto de religión: fuente de verdad absoluta, relación personal con Dios, equiparación o no con la moral universal, necesidad o no de la razón en el acercamiento a la religión, ateísmo o indiferentismo. Así mismo hemos visto la íntima relación entre catolicismo y libertad o catolicismo y progreso. Como consecuencia del contenido del concepto de religión se interpretaron de formas diferentes los conceptos de tolerancia o de intolerancia y se enfocaron las relaciones con las otras religiones en el pasado o en el presente. Las reflexiones recogidas en este trabajo de los diputados liberales, demócratas y republicanos así como de los periódicos afines, nos muestran en gran parte las características que adoptaron el liberalismo católico o el catolicismo liberal en España y los precursores del krausismo.

Partíamos de la hipótesis de que, siendo la cuestión religiosa un tema sensible que, hoy en día como en el pasado, tocaba de lleno las creencias individuales, en estos debates se iba a manifestar la mayor parte de las veces más el sentimiento personal sobre la cuestión que la posición de partido. Además pensábamos, como otros autores anteriores, que las medidas anticlericales que se tomaron en este período eran tomadas por diputados creyentes, la mayor parte de los cuales no ponía en cuestión el dogma. Su deseo era reformar la institución eclesiástica. Y esto se tenía que manifestar al dotar de contenido a los diferentes conceptos que hemos analizado. Hasta las fechas consideradas en este estudio, el sustrato común subyacente seguía siendo el creyente: la religión seguía siendo considerada un elemento fundamental para la vida de los hombres y de las sociedades pero el clima no estaba maduro para permitir el asentamiento de otras religiones en igualdad de condiciones con la católica.

\section{FUENTES}

Diario de Sesiones de las Cortes Constituyentes. 1870. Madrid: Imprenta J. A. García.

\section{BIBLIOGRAFÍA}

Alonso, G. 2014. La nación en capilla. Ciudadanía católica y cuestión religiosa en España, 1793-1874. Granada: Comares.

Álvarez Junco, J. 1985. «El anticlericalismo en el movimiento obrero» en VV. AA., Octubre 1934: cincuenta años para la reflexión: 283300. Madrid: Siglo XXI.

Aubert, P. (ed.). 2002. Religión y sociedad en España (siglos XIX y XX). Madrid: Casa de Velázquez.

Barrero Ortega, A. 2006. La libertad religiosa en España. Madrid: CEPC. Brelich, A. 1989 [1a edición 1977]. «Prolegómenos a una Historia de las Religiones» en H. Ch. Puech (ed.), Historia de las Religiones. Las Religiones antiguas: vol. I, 30-97. Madrid: Siglo XXI.

Callahan, W. J. 1989. Iglesia, poder y sociedad en España, 1750-1874. Madrid: Nerea.

Cruz, R. (ed.) 1997. El anticlericalismo. Madrid: Marcial Pons.

De la Fuente Monge, G. 2001. «El enfrentamiento entre clericales y revolucionarios en torno a 1869». Ayer 44: 127-150.

De Puelles Benítez, M. 1986. Educación e ideología en la España contemporánea. Barcelona: Labor.

Diez de Velasco, F. 2012. Religiones en España: historia y presente. Madrid: Akal.

González Manso, A. I. 2014. «Tolerancia religiosa y modelo de Iglesia en España en la primera mitad del siglo XIX». Historia Constitucional 15: 113-153. 
González Manso, A. I. 2015. «Reformulando los conceptos asimétricos: la simetría de la asimetría». História da Historiografia 19: 142-158. https://doi.org/10.15848/hh.v0i19.901

Hibbs-Lissorgues, S. 1995. Iglesia, prensa y sociedad en España (18681904). Alicante: Instituto Juan Gil-Albert.

Koselleck, R. 1993. Futuro pasado. Para una semántica de los tiempos históricos. Barcelona: Paidós.

La Parra López, E. y Suárez Cortina, M. (eds.). 1998. El anticlericalismo español contemporáneo. Madrid: Biblioteca Nueva.

Lamennais, F. 1834a. Paroles d'un croyant. Paris: E. Renduel.

Lamennais, F. 1834b. Palabras de un creyente. Marsella: imp. J. Barile y Boulouch. [Trad. J. Bauzá].

Llamazares Fernández, D. 2011. Derecho de la Libertad de Conciencia. Pamplona: Reuters.

Maravall, J. A. 1972. "Sobre los orígenes y sentido del catolicismo liberal en España», en Homenaje a Aranguren: 229-266. Madrid: Revista de Occidente.

Moliner Prada, A. 1998. "Anticlericalismo y revolución liberal (1833-1874)», en E. la Parra López y M. Suárez Cortina (eds.),
El anticlericalismo español contemporáneo: 69-125. Madrid: Biblioteca Nueva.

Perlado, P. A. 1970. La libertad religiosa en las constituyentes del 69. Pamplona: Universidad de Navarra.

Petschen, S. 1974. Iglesia-Estado un cambio político. Las Constituyentes de 1869. Madrid: Taurus.

Revuelta González, M. 1999. El anticlericalismo español en sus documentos. Barcelona: Ariel.

Revuelta González, M. 2002. «El anticlericalismo español en el siglo XIX», en P. Aubert (ed.), Religión y sociedad en España (siglos XIX y $X X)$ : 155-178. Madrid: Casa de Velázquez.

Souto Paz, J. A. 1992. Derecho eclesiástico del Estado. El derecho de la libertad de ideas y creencias. Madrid: Marcial Pons.

Suárez Cortina, M. 2014. Entre cirios y garrotes. Política y religión en la España Contemporánea, 1808-1936. Santander: Universidad de Cantabria, Cuenca: Universidad de Castilla-La Mancha.

VV. AA. 2014. La tolerancia religiosa en la España contemporánea. Madrid: Casa de Velázquez, Mélanges de la Casa de Velázquez. 